\title{
The Simulation of the Interplanetary Travel of the Solar Sail Spacecraft to the Potentially Hazardous Asteroid
}

\author{
Roman M. Khabibullin* and Olga L. Starinova ${ }^{1}$ \\ ${ }^{1}$ 443086, Russia, Samara, Moscow highway, 34 \\ *Corresponding author
}

\begin{abstract}
This paper discusses interplanetary travel, especially flight to the asteroids, by means of spacecraft which use solar sail instead of an engine and a propellant. The design model of the solar sail spacecraft "Helios" which created in computer-aided design system is described. The mathematical motion model for such type of spacecraft is considered and used for motion simulation session. The simulation of flight to the potentially hazardous asteroid is performed with the aid of special software complex which is developed for the purpose of this work.
\end{abstract}

Keywords-spacecraft; solar sail; potentially hazardous asteroid; mathematical motion model; heliocentric coordinate system; motion simulation

\section{INTRODUCTION}

Research into interplanetary travel and circumsolar space provides an opportunity to answer many fundamental scientific questions and to use the achievements of astronautics for exploiting the virtually unlimited resources of the Solar system. Scientific research in space requires considerable expenditure and does not ensure fast returns [1, 4, 7].

Presently, the world's leading space nations are actively developing missions to various planets of the Solar system. A promising way of cost reduction for such missions is the use of advanced physical principles of space travel. One of those it the development of solar sailing technology, which allows considerable saving in energy [6].

The greatest advantage of solar sailing concept is that it allows the creation of propellant free systems, meaning that they can accelerate indefinitely. Absence of propellant means a major saving of mass, and, together with the fact that there is no engine, the energy to mass ratio of the spacecraft can be very high. Both these factors together mean that solar sail spacecraft are able to reach high velocities, which is crucial for deep interplanetary travel and especially interstellar travel [2].

\section{THE DESIGN MODEL OF THE SMALl SOLAR SAIL SPACECRAFT}

Solar sails are a form of spacecraft propulsion that accelerates by means of pressure of stellar radiation on large ultra-thin mirrors.
At present, all solar sails are launched into space being carefully folded to fit in the upper stage of the launch vehicle, and deployed when the spacecraft is in space. The sails are generally made of three-layered film. The layer which faces the Sun is made of highly reflective aluminum, which is fixed to the central layer of a plastic substrate. One commonly used substrate is Kapton. Kapton is a general-purpose film which has been used successfully in various applications at temperatures as low as $-269^{\circ} \mathrm{C}\left(-452^{\circ} \mathrm{F}\right)$ and as high as $400^{\circ} \mathrm{C}$ $\left(752^{\circ} \mathrm{F}\right)$. The film can be laminated, metallized, punched, formed or adhesive coated. Kapton is the recommended choice for applications that require an all-polyimide film with an excellent balance of properties over a wide range of temperatures [3].

This paper describes the design of a small solar sail spacecraft "Helios" which is equipped electro optical device, solar sail and solar sail deployer.

The goals of the small spacecraft "Helios” project include:

- to solve educational, experimental, scientific and technical problems;

- to perform potentially hazardous asteroid observation;

- to determine size, mass, velocity and rotation rate of an asteroid;

- to perform surface mapping of an asteroid;

- to demonstrate industrial, scientific and technical capacity of manufacturing and educational centers of Samara Region of Russia.

The technical specifications for small spacecraft "Helios" include:

- to demonstrate the advantages of solar sailing.

- to control over reception, storage and transmission of information connected with the operation of the research equipment.

The weight-size parameters of the solar sail spacecraft are given in Table 1. The general view and the main component parts of "Helios" are given in Figure 1. 
TABLE I. WEIGHT-SIZE PARAMETERS

\begin{tabular}{|l|l|}
\hline Parameter's name & Value \\
\hline Length, $\mathrm{m}$ & 0,5 \\
\hline Width, $\mathrm{m}$ & 0,4 \\
\hline Height, $\mathrm{m}$ & 1,2 \\
\hline Mass, kg & 83,7 \\
\hline Solar sail area, $\mathrm{m}^{2}$ & 700 \\
\hline
\end{tabular}
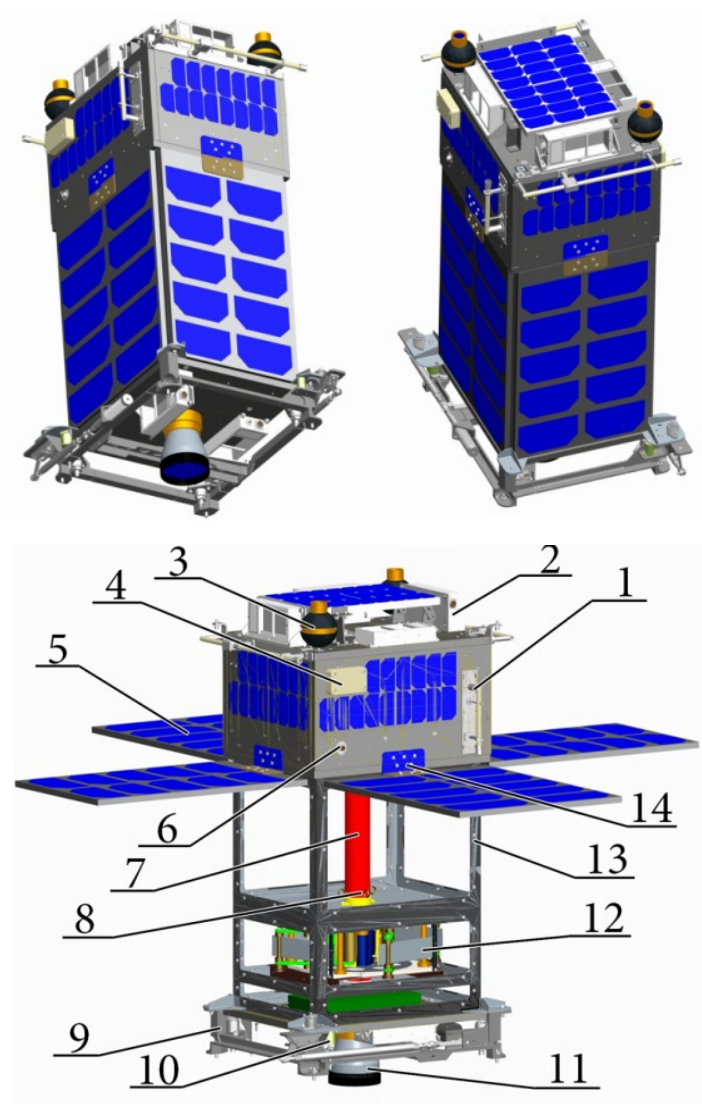

FIGURE I. GENERAL VIEW AND MAIN COMPONENT PARTS OF THE SMALL SPACECRAFT "HELIOS"

1 - ANTENNA FEEDER SYSTEM, 2 - SYSTEM ORIENTATION

EQUIPMENT, 3 - FREE-FLYING CAMERA; 4 - AUTOMATIC CONTROL MODULE, 5 - SOLAR CELL BATTERY, 6 - PRODUCTION BREAK, 7 - FIXING TUBE, 8 - SOLAR SAIL ATTACHING LUG, 9 SEPARATION DEVICE, 10 - FEELER GAGE, 11 - ELECTRO OPTICAL DEVICE, 12 - DEPLOYER, 13 - FRAME, 14 - SOLAR CELL BATTERY ATTACHING LUG

The general view of the small spacecraft "Helios" with deployed solar sail is given in Figure 2:

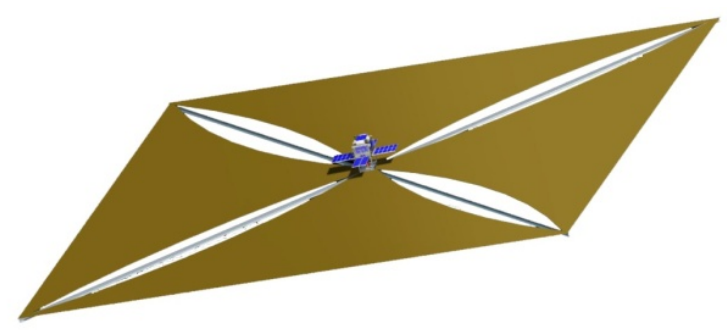

FIGURE II. GENERAL VIEW OF THE SMALL SPACECRAFT "HELIOS" (SOLAR SAIL DEPLOYED)

\section{Mathematical Motion Model}

Solar sail spacecraft doesn't demand a propellant on a board; it has little and constantly operating acceleration that allows to reach a great velocity for performing special energyintensive maneuver [5].

During interplanetary travel solar sail spacecraft moves under sunlight influence. The propulsive power of the solar pressure is determined as:

$$
F=F_{\text {incedent }}+F_{\text {reflective }}=\frac{S_{r}}{C} \cdot S(\vartheta) \cdot \cos (\vartheta)+\varepsilon \cdot \frac{S_{r}}{c} \cdot S(\vartheta) \cdot \cos (\vartheta)
$$

Here $S r$ is energy of solar electromagnetic wave which strike upon surface unit; c is velocity of light; $S(\vartheta)$ is current sail spread, $S(\vartheta)=S \cdot \cos (\vartheta)$; $\varepsilon$ is reflecting coefficient of a solar sail surface; $\vartheta$ is angle of incidence (angle between solar sail surface normal and radius vector).

In case of a perfectly-reflection solar sail surface $\varepsilon=1$ and the propulsive power direction is the same as solar sail surface normal. In this instance the propulsive power is determined as:

$$
F=2 \cdot \frac{S_{r}}{C} \cdot S \cdot \cos ^{2}(\vartheta)
$$

The motion model of the perfect-reflection solar sail is shown on Figure 3.

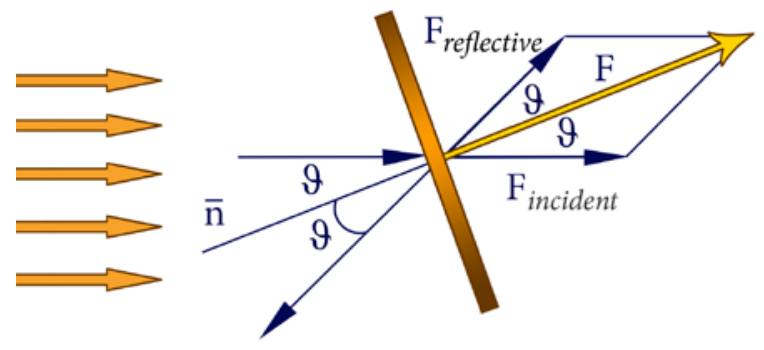

FIGURE III. MOTION MODEL OF THE PERFECT-REFLECTION SOLAR SAIL

The motion equations in the heliocentric coordinate system are:

$$
\left\{\begin{array}{l}
\frac{d r}{d t}=V_{r} \\
\frac{d F i}{d t}=\frac{d V_{f i}}{r} \\
\frac{d V_{r}}{d t}=\frac{V_{f i}^{2}}{r}-\frac{1}{r^{2}}+a_{r} \\
\frac{d V_{f i}}{d t}=-\frac{V_{r} \cdot V_{f i}}{r}+a_{f i}
\end{array}\right.
$$


Here $r$ is distance of spacecraft and Sun centers of mass; $F i$ is spacecraft longitude; $V_{r}$ is spacecraft radial velocity; $V_{f i}$ is spacecraft transversal velocity; $a_{r}$ is spacecraft radial acceleration; $a_{f i}$ is spacecraft transversal acceleration.

The complex acceleration is determined as:

$$
a_{0}=\frac{F}{m}=\frac{2 \cdot S_{r} \cdot S \cdot \cos ^{2}(\vartheta)}{c \cdot m}
$$

Here $m$ is spacecraft mass.

Such motion equations and motion model are used in software complex which oriented for motion simulation in the heliocentric coordinate system.

\section{Motion Simulation}

In this part of paper the motion simulation of the solar sail spacecraft to a potentially hazardous asteroid is considered. The simulation is performed by means special software complex which is developed for the purpose of this work. The aim of the simulation session is asteroid 433 Eros rendezvous. The asteroid orbit is shown in Figure 4. Boundary conditions of the simulation are given in Table 2.
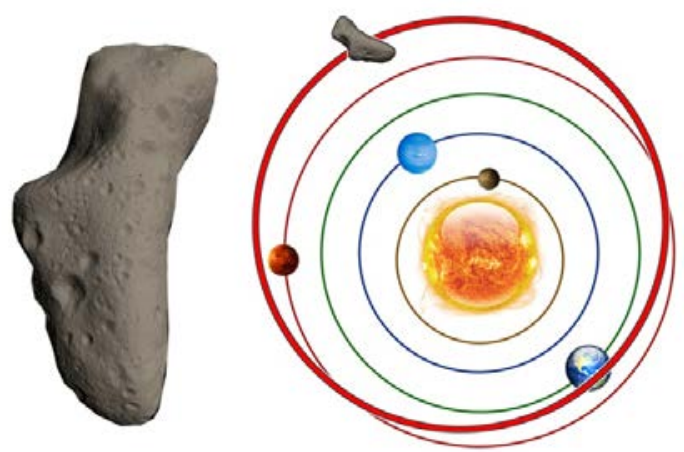

FIGURE IV. ASTEROID 433 EROS ORBIT

TABLE II. BOUNDARY CONDITIONS OF THE MOTION SIMULATION

\begin{tabular}{|l|l|}
\hline Parameter's name & Value \\
\hline Destination & 433 Eros \\
\hline Start date & $19^{\text {th }}$ Oct. 2028 \\
\hline Finish date & $14^{\text {th }}$ Dec. 2030 \\
\hline Spacecraft mass $m, \mathrm{~kg}$ & 83,7 \\
\hline Sail spread $S, \mathrm{~m}^{2}$ & 700 \\
\hline Angle of incidence 9 , grad & 35,7 \\
\hline
\end{tabular}

The suppositions which are used during simulation session include following points:

- to use the case of perfect-reflection solar sail;

- angle of incidence $\vartheta=$ const.

At the end of simulation process we receive the following results:

- the flight time of the solar sail spacecraft to the asteroid 433 Eros is 786 days;

- the trajectory of the flight is given in Figure 5;
- dependency graphs of the flight parameters against time are shown in Figure 6.

The results of this simulation session are evidence that solar sail spacecraft is capable of taking a flight to a space object of interest.

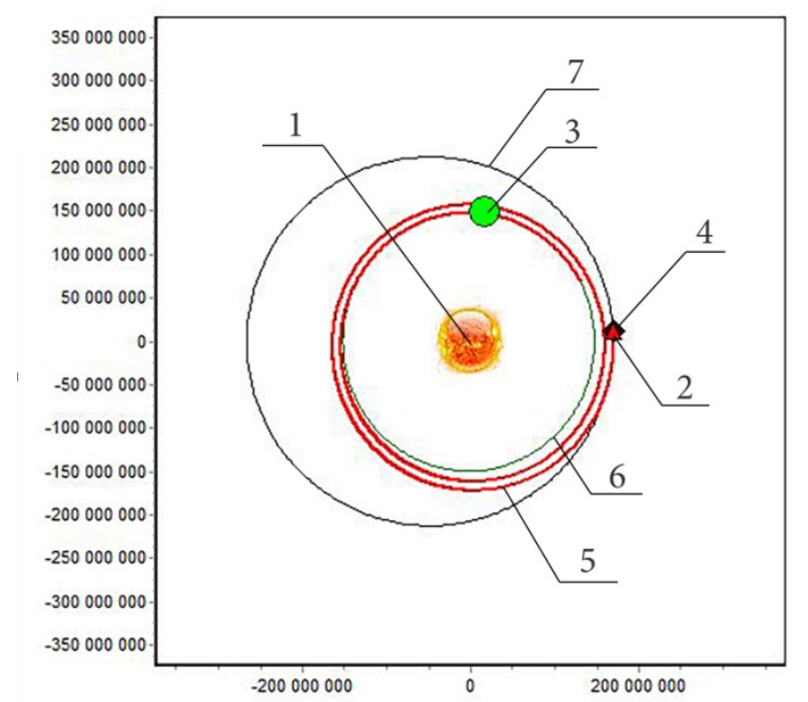

FIGURE V. TRAJECTORY OF THE FLIGHT

1 - SUN, 2 - SOLAR SPACECRAFT, C3 - EARTH, 4 - ASTEROID 433

EROS, 5 - SPACECRAFT TRAJECTORY, 6 - EARTH ORBIT, 7 ASTEROID ORBIT

\section{CONCLUSION}

This paper consists of three main parts. At the first step the design model of the solar sail spacecraft "Helios" which created in computer-aided design system is described. At the second part the motion under sunlight influence is considered. Also the motion model is created. Such model is used at the third step which includes the simulation session of flight to the asteroid 433 Eros. As a result, the flight trajectory, dependency graphs of the flight parameters against time are obtained. Moreover, results of this paper demonstrate possibility of usage solar sail spacecraft for interplanetary travel and flight to potentially hazardous asteroids.

\section{REFERENCES}

[1] Gregory L. Matloff, Les Johnson, C Bangs, "Living Off the Land in Space: Green Roads to the Cosmos", Springer Science + Business Media, LLC, 2007, pp. 153-158.

[2] Information on http://interplanetarytravelandtheuniverse.webs.com.

[3] Information on http://www.kapton.dupont.com.

[4] Olga L. Starinova, Dmitriy V. Kurochkin and Irina L. Materova, "Optimal control choice of non-Keplerian orbits with low-thrust propulsion” AIP Conf. Proc., 2012.

[5] Olga Starinova, Irina Gorbunova, "Analytical control laws of the heliocentric motion of the solar sail spacecraft”, 2014.

[6] Pavel Kazmerchuk " Development of program software of optimization of trajectories of solar sail spacecraft”, Izvestia RAS, 2007.

[7] Y. Tsuda, O. Mori, R. Funase, H. Sawada, T. Yamamoto, T. Saiki, T. Endo, and J. Kawaguchi, "Flight status of IKAROS deep space solar sail demonstrator,” Acta Astronautica, vol. 69, no. 9\&10, pp. 833-840, 2011. 

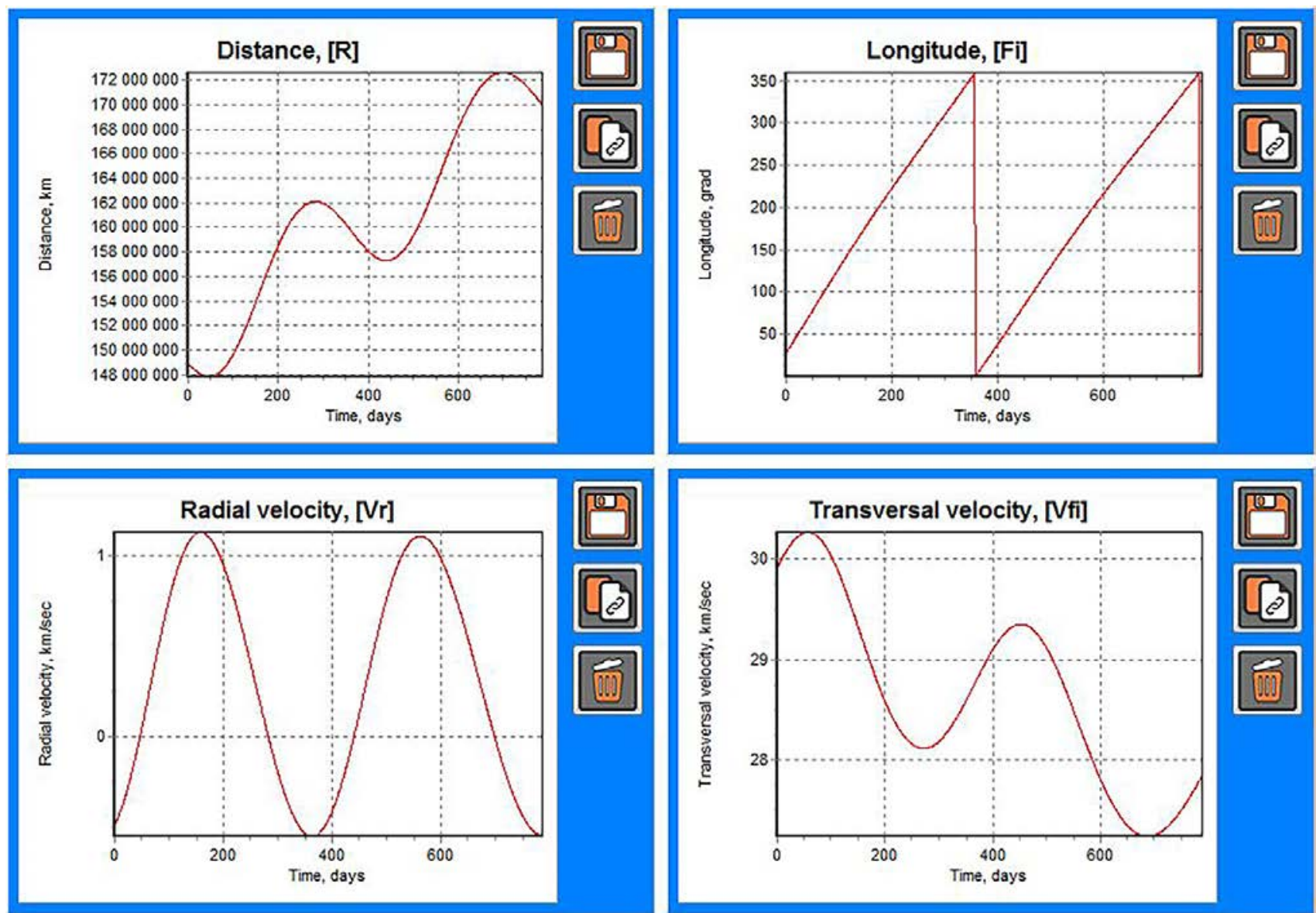

FIGURE VI. DEPENDENCY GRAPHS OF THE FLIGHT PARAMETERS AGAINST TIME 